
n. 3, p. 464-467, julho-setembro 2003.

\title{
Distribuição vertical e setorial das ninfas de mosca-branca nas folhas do meloeiro
}

\author{
Francisco Roberto de Azevedo $^{1}$; Ervino Bleicher ${ }^{2}$
}

${ }^{1}$ Secretaria da Agricultura Irrigada do estado do Ceará, Centro Administrativo Gov. Virgílio Távora, Cambeba, Ed. SEAD, s/n 60839-900 Fortaleza-CE; ${ }^{2}$ UFC, Depto. Fitotecnia, C. Postal 12168, 60356-001 Fortaleza-CE; E-mail: roberto@seagri.ce.gov.br

\section{RESUMO}

Foram realizados estudos, no campo experimental de Pacajús, da Embrapa Agroindústria Tropical, para observar a distribuição espacial das ninfas de Bemisia argentifolii Bellows \& Perring (Hemiptera: Aleyrodidae), entre as folhas e nas folhas da rama do meloeiro. Para estudo da distribuição entre as folhas, foram amostradas aleatoriamente, as folhas presentes no intervalo entre a quinta e a vigésima folha. A contagem das ninfas foi realizada semanalmente aos 49; $56 \mathrm{e}$ 63 dias após o plantio, retirando, com o auxílio de um vasador de cortiça, um disco foliar de $2,8 \mathrm{~cm}^{2}$. Foi observada uma maior concentração de ninfas entre a oitava e a décima folha, contada a partir da extremidade da rama do meloeiro, sendo, portanto, a melhor folha para ser amostrada. O estudo da distribuição setorial nas folhas do meloeiro foi feito amostrando-se aleatoriamente as folhas em campo e subdividindo-as em quatro setores, delimitados pela nervura central em esquerdo distal (ED), esquerdo proximal (EP), direito proximal (DP) e direito distal (DD). As ninfas concentraram-se mais nos setores proximais da folha do meloeiro, quando comparados aos setores distais, nas três avaliações efetuadas no campo. Estes insetos preferem os setores proximais da folha por estarem mais próximos do floema, facilitando a obtenção do alimento. Do total de ninfas contadas nos setores das folhas do meloeiro, $13,08 \%$ foram encontradas no setor ED; $35,7 \%$ no setor EP; $36,7 \%$ no setor DP e $14,25 \%$ no setor DD. Portanto, recomenda-se efetuar a amostragem das ninfas próximo à nervura central da folha do meloeiro.

Palavras-chave: Bemisia argentifolii, amostragem, melão.

\section{ABSTRACT}

Vertical and sectorial distribution of whitefly nymphs on melon leaves

The spatial nymphs distribution of Bemisia argentifolii Bellows $\&$ Perring (Hemiptera: Aleyrodidae) among and within melon leaves was observed. The vertical distribution among leaves was done, selecting randomly leaves from node $5^{\text {th }}$ through $20^{\text {th }}$. The counting of nymphs was performed on a weekly basis, at 49;56 and 63 days after planting, using a circular leaf disc with an area of $2.8 \mathrm{~cm}^{2}$. Higher nymph concentration was observed from the $8^{\text {th }}$ to the $10^{\text {th }}$ leaf counted from the top to the bottom of the melon plant. These leaves were considered the best ones to be sampled. The distribution of nymphs over the leaf sectors was performed, selecting randomly leaves and dividing them into four sectors (distal left, proximal left, distal right, and proximal right). The number of nymphs was similar in both proximal sectors, however in the proximal sectors the number of nymphs was greater than those found in distal sectors. From the total nymphs found, $13.70 \%$ were found on distal left sector, $35.70 \%$ on proximal left sector, 36.70 on proximal right sector and $14.25 \%$ on distal right sector. Sampling nymphs close to the central leaf rib is more effective.

Keywords: Bemisia argentifolii, sampling, melon.

\section{(Recebido para publicação em 21 de dezembro de 2001 e aceito em 24 de abril de 2003)}

\begin{abstract}
$\mathrm{A}_{\mathrm{B}}$ mosca-branca, Bemisia argentifolii Bellows \& Perring (Hemíptera: Aleyrodidae), tem se tornado nos últimos anos, a praga mais importante da cultura do melão em diversos estados brasileiros, pelas perdas que vem ocasionando à cultura. Aplicações foliares de inseticidas têm sido pouco eficientes, principalmente pelo fato das ninfas (aproximadamente 96\%) se localizarem na face inferior das folhas do meloeiro (Simmons \& McCreight, 1996) e as plantas apresentarem um crescimento rasteiro, dificultando as pulverizações.

O desenvolvimento de um método de amostragem eficiente é fundamental para o estudo da dinâmica populacional da praga e para estabelecer critérios na implementação de um programa de
\end{abstract}

manejo integrado de pragas. Para a cultura do algodão, a contagem de todas as ninfas presentes em uma folha é o método mais confiável para se determinar a densidade populacional do inseto-praga (Ohnesorge \& Rapp, 1986). Porém, o método é cansativo e demanda muito tempo para ser realizado, tornando-se mais fácil se restringido à área examinada em uma única parte da folha (setor).

As ninfas de mosca-branca, a partir do $2^{\circ}$ instar, são sésseis, de modo que a localização da folha infestada e o período fisiológico de desenvolvimento da planta hospedeira seguem uma distribuição linear, apresentando assim, um padrão definido de distribuição na planta. A presente pesquisa foi desenvolvida para avaliar a distribuição vertical das ninfas de $B$. argentifolii entre as folhas da rama do meloeiro e a distribuição setorial dentro da folha, visando orientar o produtor de melão na escolha do local da planta a ser amostrado quando da tomada de decisão sobre o controle ou não da praga.

\section{MATERIAL E MÉTODOS}

O estudo da distribuição vertical das ninfas nas folhas da rama do meloeiro foi realizado no campo experimental da Embrapa Agroindústria Tropical, em Pacajús (CE) de 10/10 a 19/12/00, em uma área de $900 \mathrm{~m}^{2}$. O delineamento experimental adotado foi o inteiramente casualizado, sendo os tratamentos representados por 16 folhas do meloeiro 


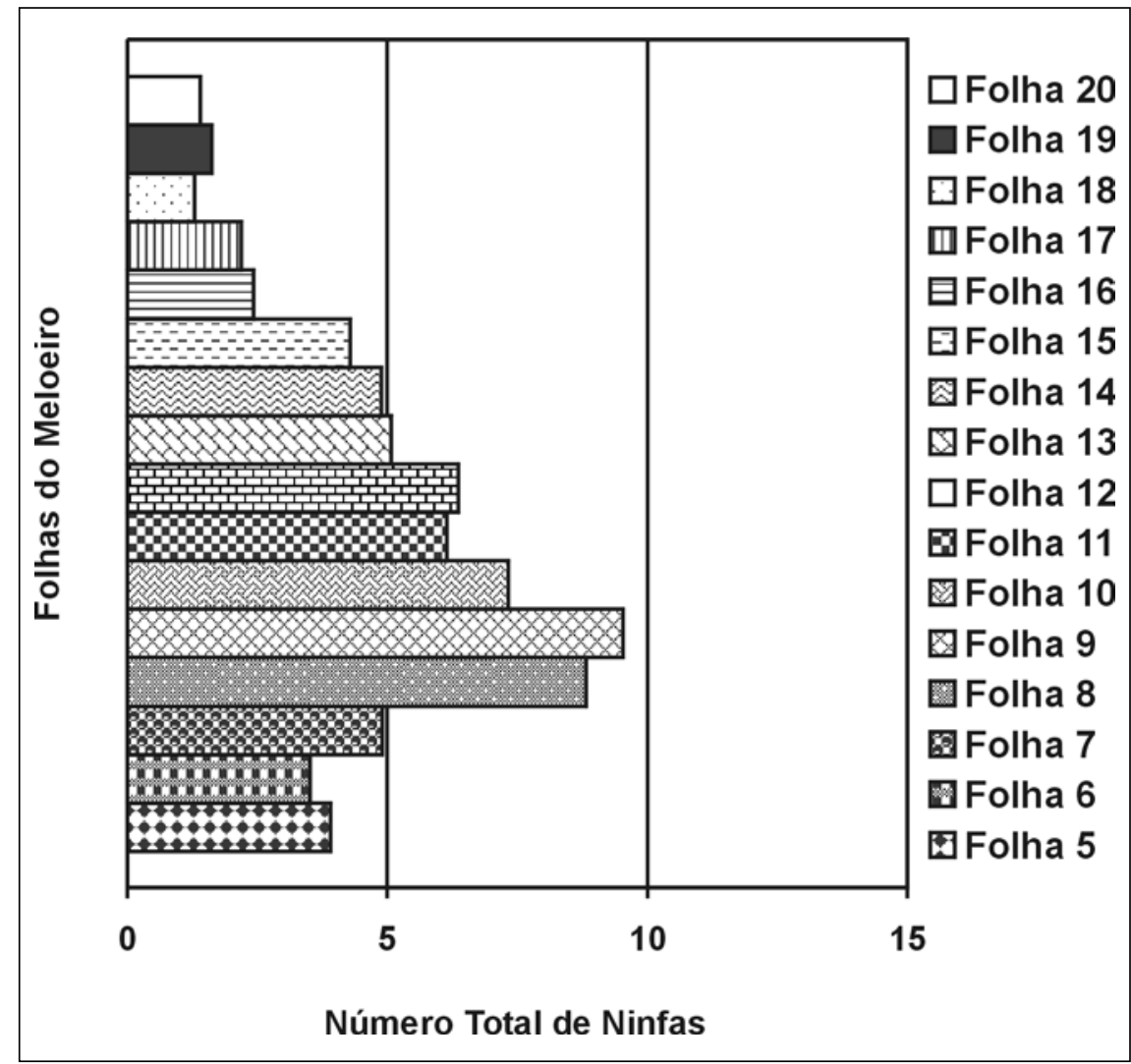

Figura 1. Número total de ninfas de Bemisia argentifolii Bellows \& Perring (Hemíptera: Aleyrodidae) em folhas da rama do meloeiro, em três avaliações de campo. Pacajús, Embrapa Agroindústria Tropical, 2000.

da variedade Cantaloupe (híbrido HyMark), da quinta até a vigésima folha, distribuídos em quatro repetições, cada uma composta de 10 folhas. Portanto, cada tratamento consistiu de 40 folhas, totalizando 640 folhas amostradas em cada período amostral. De cada folha amostrada foi retirado, com o auxílio de um vazador de cortiça, um círculo foliar de $2,8 \mathrm{~cm}^{2}$, colocando-o dentro de um saquinho plástico transparente devidamente identificado. Em seguida, foram acondicionados em uma caixa de isopor, para não perderem a umidade e levados ao laboratório de entomologia, onde foram contadas todas as ninfas presentes no disco foliar, através da observação em uma lupa de mesa. A coleta dos discos foliares foi realizada semanalmente aos 49,56 e 63 dias após o plantio.

O estudo da distribuição setorial das ninfas dentro da folha do meloeiro foi realizado no mesmo local do estudo anterior, de 28/11/00 a 30/01/01, em uma área de $672 \mathrm{~m}^{2}$. O delineamento experimental adotado foi o inteiramente casualizado, sendo os tratamentos representados por quatro setores da folha do dos pela nervura central em direito distal (DD), direito proximal (DP), esquerdo distal (ED) e esquerdo proximal (EP), distribuídos em quatro repetições, cada uma composta de 15 folhas. Portanto, cada tratamento consistiu de 60 folhas, totalizando 240 folhas em cada período amostral. As folhas foram cortadas na altura do pecíolo com um estilete e colocadas em sacos plásticos transparentes, acondicionados em uma caixa de isopor. Contou-se o número de ninfas em cada setor foliar, utilizando uma lupa de mesa. Os números médios de ninfas por disco foliar foram transformados em $\sqrt{X+0,5}$ para fins de cálculos estatísticos. Os dados foram submetidos à análise de variância e as médias comparadas pelo teste de Student-NeumanKeul's (P£0,05).

\section{RESULTADOS E DISCUSSÃO}

A distribuição vertical das ninfas de $B$. argentifolii nas folhas da rama do meloeiro (híbrido Hy-Mark), delimita- meloeiro apresenta um padrão mais definido do que os adultos (Tabela 1). Aos 49 dias, de forma estatisticamente significativa, elas se distribuíram no intervalo da oitava à décima-segunda folha. Aos 56 dias, distribuíram-se da sexta à décima-quinta folha e aos 63 dias, diminuíram o intervalo, distribuindo-se da sétima à décima-segunda folha. As poucas ninfas encontradas da décima-sexta à vigésima folha nas três avaliações estavam próximas de se transformarem em adultos e são erroneamente chamadas de "pupas". Verificou-se que as ninfas distribuem-se nas folhas maduras e as "pupas", nas folhas mais velhas.

De acordo com o número total de ninfas encontrado nas três avaliações de campo, verificou-se que o número aumentou progressivamente até a nona folha. Desta folha em diante, reduziuse consideravelmente ao longo da rama, encontrando-se um menor número na décima-oitava, décima-nona e vigésima folha (Figura 1). Levando-se em consideração a média geral das três avaliações, observou-se, no entanto, que de forma estatisticamente significativa, as ninfas distribuíram-se no intervalo da oitava à décima folha (Tabela 1). Na cultura do algodoeiro, Ohnesorge \& Rapp (1986) verificaram que as ninfas de terceiro e quarto instares podem ser amostradas entre a terceira e sétima folha, enquanto que Gerling et al. (1980) reportaram que a posição média das folhas infestadas do algodoeiro SJ2 pelas "pupas" altera da sexta folha em julho para a décima primeira folha em agosto. No entanto, Melamed-Madjar et al. (1982), observaram uma mudança da quinta à sexta folha em junho para a sétima e oitava folha em julho. De acordo com os resultados desses autores, podese constatar que este inseto apresenta um comportamento ligeiramente diferente na cultura do meloeiro. Por isso, a relação entre a localização da maioria das folhas infestadas e o período fisiológico de desenvolvimento da planta hospedeira provavelmente segue uma distribuição linear (Von Arx et al., 1984). Baseado nestas informações, pode-se afirmar que a folha mais indicada para amostrar ninfas de $B$. argentifolii está entre a oitava e a décima folha, contadas a partir da extremidade da rama do meloeiro. 
Tabela 1. Número médio e média geral de ninfas de Bemisia argentifolii Bellows \& Perring (Hemíptera: Aleyrodidae) por disco foliar de 2,8 $\mathrm{cm}^{2}$ nas folhas do meloeiro aos 49; 56 e 63 dias após o plantio. Pacajús, Embrapa Agroindústria Tropical, 2000.

\begin{tabular}{|c|c|c|c|c|}
\hline \multirow{2}{*}{ Tratamentos } & \multicolumn{4}{|c|}{ Dias Após o Plantio } \\
\hline & 49 & 56 & 63 & Média \\
\hline $5^{a}$ Folha & $1,00^{1}$ ef & 1,07 bcde & $1,83 \mathrm{bcd}$ & 1,30 def \\
\hline $6^{a}$ Folha & $0,70 \mathrm{f}$ & $1,75 \mathrm{abcd}$ & $1,05 \mathrm{cdef}$ & 1,17 ef \\
\hline $7^{a}$ Folha & $1,60 \mathrm{cde}$ & $1,30 \mathrm{abcd}$ & $2,00 a b c$ & $1,63 \mathrm{cde}$ \\
\hline $8^{a}$ Folha & $2,50 a b$ & 2,92 a & $3,40 a b$ & $2,94 \mathrm{a}$ \\
\hline $9^{a}$ Folha & 3,30 a & 2,73 a & $3,50 \mathrm{a}$ & $3,18 \mathrm{a}$ \\
\hline $10^{\mathrm{a}}$ Folha & $2,70 a b$ & $2,25 a b$ & $2,38 a b c$ & $2,44 a b$ \\
\hline $11^{\mathrm{a}}$ Folha & $1,8 \mathrm{abcd}$ & $2,15 a b$ & $2,20 a b c$ & $2,05 \mathrm{bcd}$ \\
\hline $12^{\mathrm{a}}$ Folha & $2,50 \mathrm{abc}$ & $1,83 a b c$ & $2,03 a b c$ & $2,12 b c$ \\
\hline $13^{a}$ Folha & $1,70 \mathrm{de}$ & $1,73 \mathrm{abcd}$ & $1,63 \mathrm{cde}$ & $1,69 \mathrm{cde}$ \\
\hline $14^{\text {a }}$ Folha & $1,60 \mathrm{cde}$ & $1,43 \mathrm{abcd}$ & $1,85 \mathrm{bcd}$ & $1,63 \mathrm{cde}$ \\
\hline $15^{\mathrm{a}}$ Folha & $1,80 \mathrm{bcd}$ & $1,38 \mathrm{abcd}$ & 1,10 cdef & $1,43 \mathrm{cde}$ \\
\hline $16^{a}$ Folha & $1,10 \mathrm{f}$ & $0,68 \mathrm{cde}$ & 0,65 def & $0,81 \mathrm{fg}$ \\
\hline $17^{a}$ Folha & $0,90 \mathrm{f}$ & 0,70 cde & 0,58 def & $0,73 \mathrm{fg}$ \\
\hline $18^{a}$ Folha & $0,40 \mathrm{f}$ & $0,48 \mathrm{de}$ & $0,40 \mathrm{f}$ & $0,43 \mathrm{~g}$ \\
\hline 19a Folha & $0,60 \mathrm{f}$ & $0,60 \mathrm{cde}$ & $0,43 \mathrm{f}$ & $0,54 \mathrm{~g}$ \\
\hline $20^{a}$ Folha & $0,50 \mathrm{f}$ & $0,40 \mathrm{e}$ & 0,50 ef & $0,47 \mathrm{~g}$ \\
\hline $\mathrm{CV}(\%)$ & 10,67 & 15,84 & 15,41 & 7,45 \\
\hline
\end{tabular}

${ }^{1}$ Dados originais transformados em $\sqrt{X+0,5}$

Médias seguidas da mesma letra, nas colunas, não diferem estatisticamente entre si, pelo teste de Student-Neuman-Keul's $(\mathrm{P} \leq 0,05)$.

Tabela 2. Número médio de ninfas de Bemisia argentifolii Bellows \& Perring (Hemíptera: Aleyrodidae) nos setores das folhas do meloeiro aos 49; 56 e 63 dias após o plantio. Pacajús, Embrapa Agroindústria Tropical, 2000.

\begin{tabular}{lcccc}
\hline \multirow{2}{*}{ Tratamentos } & \multicolumn{4}{c}{ Dias após o plantio } \\
\cline { 2 - 5 } & $\mathbf{4 9}$ & $\mathbf{5 6}$ & $\mathbf{6 3}$ & Média Geral \\
\hline Direito Distal & $0,98^{1} \mathrm{~b}$ & $0,49 \mathrm{~b}$ & $0,48 \mathrm{~b}$ & $0,65 \mathrm{~b}$ \\
Direito Proximal & $2,30 \mathrm{a}$ & $1,32 \mathrm{a}$ & $1,40 \mathrm{a}$ & $1,67 \mathrm{a}$ \\
Esquerdo Distal & $0,87 \mathrm{~b}$ & $0,42 \mathrm{~b}$ & $0,50 \mathrm{~b}$ & $0,60 \mathrm{~b}$ \\
Esquerdo Proximal & $2,20 \mathrm{a}$ & $1,32 \mathrm{a}$ & $1,40 \mathrm{a}$ & $1,64 \mathrm{a}$ \\
\hline $\mathrm{CV}(\%)$ & 8,52 & 9,02 & 12,61 & 11,77 \\
\hline
\end{tabular}

${ }^{1}$ Dados originais transformados em $\sqrt{X+0,5}$

Médias seguidas da mesma letra, nas colunas, não diferem estatisticamente entre si, pelo teste de Student-Neuman-Keul's $(\mathrm{P} \leq 0,05)$.

Com relação à distribuição setorial, observou-se que as ninfas concentraram-se mais nos setores proximais (DP e EP) da folha do meloeiro, quando comparada com os setores distais (DD e ED), nas três avaliações efetuadas no campo (Tabela 2). Como a mosca-branca apresenta estiletes curtos, a proximidade com a nervura central, por onde passa a maior parte dos fotoassimilados elaborados pela folha após a fotossíntese, deve facilitar a captação do alimento
(Van Lenteren \& Noldus, 1990). Ohnesorge \& Rapp (1986) afirmaram que a contagem de todas as formas imaturas presentes em uma folha é o método mais confiável para se determinar a densidade populacional de uma praga. No entanto, essa metodologia é muito cansativa e demanda muito tempo, podendo se reduzir o tempo, restringindose à área examinada em setores da folha. Von Arx et al. (1984), constataram que nos campos sudanenses de algodão, o local de amostragem deve ser escolhido de acordo com a idade das folhas e que somente um setor de cada folha pode ser examinado, sendo que o tamanho da folha é determinado de acordo com a densidade da mosca-branca e de um nível de precisão previamente definido. Recomendam ainda que a contagem das ninfas de terceiro e quarto instares deve ser feita somente nos setores próximos à nervura central das folhas de algodão, observando que, para cada 
variedade, o número relativo de moscabranca em cada setor da folha deve ser estabelecido separadamente. Naranjo \& Flint (1994), trabalhando com a mesma cultura, observaram que as ninfas de Bemisia tabaci se distribuem igualmente entre os quatro setores da folha, delimitados pela nervura central, sendo esse padrão independente da localização da folha na planta, cultivar ou período amostral, mudando, no entanto, ligeiramente com a data amostral. De acordo com os autores, um disco de $3,88 \mathrm{~cm}^{2}$ da base do setor esquerdo proximal da quinta folha é suficiente para estimar a densidade de ninfas, as quais se distribuem de forma não aleatória em todas as folhas do algodoeiro, agregando-se próximas do pecíolo da folha. As vantagens da utilização da folha toda, setor ou disco para estimar a densidade das ninfas depende da variância dos dados e do tempo de amostragem.

Do total de ninfas contadas nos setores das folhas do meloeiro, $13,08 \%$ foram encontradas no setor ED; 35,7\% no setor EP; $36,7 \%$ no setor DP e
$14,25 \%$ no setor DD, evidenciando que as ninfas concentraram-se mais nos setores proximais das folhas do meloeiro. Ohnesorge \& Rapp (1986), constataram também que, de todas as ninfas de terceiro e quarto instares contadas nos setores delimitados pela nervura central na folha do algodão, 21,3\% foram encontradas no setor ED; $27,2 \%$ no setor EP; $28,5 \%$ no setor DP e $23 \%$ no setor DD. Estes resultados assemelham-se aos da presente pesquisa, pois as moscas mostram uma preferência pelos setores proximais das folhas do meloeiro.

De acordo com o comportamento de alimentação deste inseto e das observações realizadas neste trabalho, recomenda-se efetuar a amostragem das ninfas próximo à nervura central da folha do meloeiro.

\section{LITERATURA CITADA}

GERLING, D.; MOTRO, U.; HOROWITZ, A.R. Dynamics of Bemisia tabaci (Gennadius) (Homoptera: Aleyrodidae) attacking cotton in the Coastal plain of Israel. Bulletin of Entomological Research, v. 70, p. 213-219, 1980.
MELAMED-MADJAR, V.; COHEN, S.; CHEN, M.; TAM, S.; ROSILIO, D. A method for monitoring Bemisia tabaci Gennadius and timing splay applications against the pest in cotton field in Israel. Phytoparasitica, v. 10, p. 85-91, 1982.

NARANJO, S.E.; FLINT, H.M. Spatial distribution of preimaginal Bemisia tabaci (Homoptera:Aleyrodidae) in cotton and development of fixed-precision sequential sampling plans. Environmental Entomology, v. 23, n. 2, p. 254-266, 1994.

OHNESORGE, B.; RAPP, G.M. Methods for estimating the density of whitefly nymphs (Bemisia tabaci Genn.) in cotton. Tropical Pest Management, v. 32, n. 3, p. 207-211, 1986.

SIMMONS, A.M.; McCREIGHT, J.D. Evaluation of melon for resistance to Bemisia argentifolii (Homoptera:Aleyrodidae). Journal of Economic Entomology. v. 89, n. 6, p. 1663-1668, 1996.

VAN LENTEREN, J.C.; NOLDUS, L.P.J.J. Whitefly-relationships: behavioral and ecological aspects, p. 47-89. 1990 In: GERLING, D. Whiteflies: their bionomics, pest status and management. Hampshire, England, 1990, p. 4789.

VON ARX, R.; BAUMGARTNER, J.; DELUCCHI, V. Sampling of Bemisia tabaci (Genn.)(Sternorrhyncha: Aleyrodidae) in Sudanese cotton fields. Journal Economic Entomology, v. 77, p. 1130-1136, 1984. 